\title{
A Mini Review - Pharmaceutical Creams
}

\author{
Sameeha Khare ${ }^{1}$, Shalaka Abhyankar ${ }^{1}$, Ashwin Kuchekar ${ }^{1 *}$, Ashwini Gawade ${ }^{1}$
}

${ }^{1}$ School of Pharmacy, Dr. Vishwanath Karad MIT World Peace University, Pune, Maharashtra 411038, India

DOI: $10.36347 /$ sajp.2021.v10i04.001

| Received: 06.03.2021 | Accepted: 27.03.2021 | Published: 02.04.2021

*Corresponding author: Dr. Ashwin Kuchekar

Abstract

Creams are pharmaceutical products that are widely used to treat a variety of skin conditions. Creams were traditionally made by combining two or more ingredients with water as the solvent. Newer methods for cream formulation are being used as technology advances. The public and society can safely use these semi-solid preparations. They have a wide range of functions. The origin, lifestyle, age, and state of health are all reflected in the skin. Colour, tone, and evenness of the skin, as well as pigmentation and skin surface characteristics, are all indicators of skin health. Skin care products are widely available and play an important role in health and nursing care. The emphasis on skin care is shifting as people get older. Soothing, restoring, and reinforcing become more important, and cleansing should be done with caution. As people get older, their skin's structure and function change, making them more vulnerable to a variety of clinically relevant skin problems.

Keywords: Cream, Emulsion, Skin Products, Topical, Drug delivery, Process.

Copyright (C) 2021 The Author(s): This is an open-access article distributed under the terms of the Creative Commons Attribution 4.0 International License (CC BY-NC 4.0) which permits unrestricted use, distribution, and reproduction in any medium for non-commercial use provided the original author and source are credited.

\section{INTRODUCTION}

Topical preparations that will be applied to the skin are called creams. "Liquid or semi-solid viscous emulsions with varying consistency depending on the oil and water $[1,2]$. On the idea of steps, the creams could also be prioritized in the form of o / $\mathrm{w}$ or no / o emulsions. Creams are used for a range of cosmetic functions, as well as cleansing, beautifying, improving aesthetics, protection and therapeutic functions. These topical formulations are accustomed to delivering drugs for localized impact, the underlying skin layer or tissue layer is employed. Drugs are intended to be applied topically. Creams are classified as healthy products because they are created using strategies developed within the pharmaceutical industry; each non-medicated and medicated cream is generally used to treat a spread of skin conditions or dermatoses. Developed creams are ayurvedic, herbal, or medically assisted, and people use them to treat their skin problems. They are created from one or more of the drug substances dispersed in a suitable phase $[2,3]$.

\section{Product Design and Development}

The drug product development process begins after the dosage form is chosen to develop a stable product that can achieve safety and efficacy [4].

\section{Drug Substance}

The properties of the drug substance have a significant effect on the drug product's performance and functionality. As a matter of fact, these characteristics must be determined in order to create the proper dosage form and select the appropriate concentration of drug, excipients, and process parameters. Drug characteristics such as solubility, partition coefficient $(\log$ p), particle size, pKa, permeability, melting point, and molecular weight must be identified during preformulation studies because they play a role in percutaneous penetration $[4$, 5].

\section{Composition for preparation of skin creams}

The selection of excipients should be given special attention as it has an impact on the performance, manufacturability and stability of the final product. This decision is based on the dosage form, route of administration, safety profile, manufacturing process and regulatory considerations. The release of the drug from the dosage form, the characteristics of the skin barrier and the penetration/diffusion of the drug are all influenced by the nature and concentration of the excipient, affecting the duration and extent of therapeutic action. at the target skin layer. The excipients are used to enhance the solubility and entrap the drug, to control the release, to increase the skin permeability, formulation stability, and inhibit microbial growth. Pharmaceutical excipients acceptable for the development of pharmaceutical products are listed in the international pharmacopoeias $[1,4]$. 
In cream formulations, water is a fundamental ingredient. Water is often used as a liquid vehicle in skincare products. The creams are made with water free of pesticides, pollutants, viruses and other contaminants. It can also form emulsions, depending on the amount of water used in the mixture. One of the most important components of cream is oil, fats and waxes. Depending on the application, waxes behave as an emulsifying agent, fats act as a thickening agent, and oil acts as a preservative [5]. Mineral oil is highly refined, clear, and odourless oil that does not solidify or clog skin pores, and it rarely causes allergic reactions. It is light in weight and inexpensive, and helps to reduce water loss and keep the body hydrated. Liquid paraffin, liquid petroleum, paraffin oil, liquid petrolatum, petroleum oil and other mineral oils are commonly used in cosmetics. Vegetable oil forms a layer on the skin's surface that helps the skin retain its fullness by slowing water loss. Vegetable oils can also be added to creams or personal care items to thicken the lipid or oily component like almond, seed, avocado, and sunflower [6]. Beeswax, carnauba wax, ceresin, spermaceti and other ingredients are used to make cream. Waxes are used in cosmetics as they facilitate the separation of oily and liquid components from emulsions. These waxes often thicken the lipid part of the skin and cause it to adhere to the surface. Creams are made up of many types of fats. Animals, trees and minerals will provide all of these materials. Lanolin is made from the fat of sheep's wool. Lanolin is divided into two types: hydrated and non-hydrated. Hydrated lanolin contains between $25 \%$ and $30 \%$ water. The melting point of anhydrous lanolin is 38 to $42^{\circ} \mathrm{C}$ and it has a slight odour. These ingredients serve as lubricants on the skin's surface, making it appear soft and smooth. Lanolin helps in the formation of emulsions and mixes well with other ingredients in cosmetics and personal care products. Colours were largely derived from natural substances such as turmeric, saffron, and indigo. Most skin care formulations contain these important multifunctional ingredients. Humectants are organic compounds that have high hydroscopicity. These are the materials that have the ability to absorb and hold water. These have numerous advantages, including hydration, whitening, and so on. Glycerine, hydroxyethyl urea, betaine, sodium-L-lactate, and other humectants are some examples. Humectants are also used in shampoo to help hydrate hair and counter the drying effect of surfactants [7]. They also help with low temperature stabilization and freeze / thaw, acting as antifreeze and maintaining shampoo clarity at low temperatures. A wide range of products are added to obtain a pleasant scent and mask the smell of certain ingredients. Vitamins are necessary for the proper functioning of the physiological functions of the body and the skin. Vitamins A, B, C, E and others are commonly used in the formulation of the cream [7]. Skincare products contain preservatives to help stop microbe contamination and instability during formulation, shipping, storage, and consumer use. Antioxidants are also used to counteract the effects of oxygen exposure. Synthetic preservatives are effective in preserving products when used at low concentrations. They have a wide range of antibacterial activity $[8,9]$.

\section{MANUFACTURING PROCESS \\ Preparation of the $\mathrm{o} / \mathrm{w}$ emulsion cream}

The oil-soluble and the emulsifiers are mixed in a container in a water bath. In a separate beaker of water, preservatives and water-soluble components are added. After the oil phase has been heated, it is placed in a mortar and pestle, and the water phase is gradually added and triturated until a clicking sound can be examined. At the end, preservatives and a few additives are added [10-12].

\section{Preparation of oil-free emulsion creams}

In a beaker, mix the oil-soluble components and the emulsifier. Another beaker is used to collect the water and water-soluble components. The aqueous phase should be triturated in a mortar and pestle before adding the oil phase. At the end, preservatives and a few additives are added [10-12].

\section{Evaluation parameters of creams [13, 14]}

$\mathrm{pH}$ determination: The $\mathrm{pH}$ of the cream can be determined using a sufficient amount of the formulation diluted with a solvent in a beaker of the cream at room temperature.

Physical appearance: The cream's physical appearance is determined by its colour, roughness, and texture.

Spreadability: A requisite amount of sample is divided between two glass slides, and the slides are weighted for 5 minutes with a $100 \mathrm{gm}$ weight.

Viscosity: Viscometers can be used to determine the viscosity of formulated creams.

Homogeneity: The homogeneity of the formulation was assessed visually and tactilely.

Removal: The ease with which the creams applied could be removed was tested by washing the affected area with tap water.

Type of smear: The type of film or smear formed on the skin after application of the cream was examined.

Irritancy study: Irritation, erythema, and oedema were all examined, for regular intervals up to $24 \mathrm{hrs}$ and reported.

Stability study: This study is performed on the prepared product as per the ICH guidelines. 


\section{CONCLUSION}

Almost every vehicle, including emulsifiers, surfactants, oil and butters, waxes and hydrophilic solutions, can be provided with skin care. The use of cosmetic pharmaceuticals to strengthen the beauty or health of the skin. Topical formulations have certain benefits, including ease of application and lower chances of side effects, non-invasive processes and increased patient compliance, compared to other conventional systems. As the pharmaceutical industry and sector progresses, pharmaceutical creams are assured that they will continue in the coming years as an interesting and attractive field of research.

\section{REFERENCE}

1. Chauhan L, Gupta S, Creams: A Review on Classification, Preparation Methods, Evaluation and its Applications, Journal of Drug Delivery and Therapeutics. 2020; 10(5-s):281-289

2. Tarun G, Goutam R, and Amit K. Comprehensive review on additives of topical dosage forms for drug delivery. Drug Deliv, Early Online: 1-19

3. Kumar KK. Importance of Critical Quality Attributes in Biopharmaceuticals Development. Research Journal of Topical and Cosmetic Sciences. 2019;10(1):29-33.

4. Namjoshi S, Dabbaghi M, Roberts MS, Grice JE, and Mohammed Y. Quality by Design: Development of the Quality Target Product Profile (QTPP) for Semisolid Topical Products. Pharmaceutics. 2020 Mar;12(3):287.

5. Simões A, Veiga F, Vitorino C, Figueiras A. A tutorial for developing a topical cream formulation based on the quality by design approach. Journal of pharmaceutical sciences. 2018 Oct 1; 107(10):2653-62.

6. Paudel KS, Milewski M, Swadley CL, Brogden NK, Ghosh P, Stinchcomb AL. Challenges and opportunities in dermal/transdermal delivery. Ther Deliv. 2010;1(1):109
7. Garg T, Rath G, Goyal AK. Comprehensive review on additives of topical dosage forms for drug delivery. Drug Deliv. 2015;22(8):969-987

8. Billany M. Suspensions and emulsions. In: Aulton ME, ed. Pharmaceutics the Science of Dosage Form Design. 2nd. Edinburgh, New York: Churchill Livingstone; 2002:342-357

9. Walters KA, Brain KR. Topical and transdermal delivery. In: Gibson M, ed. Pharmaceutical Preformulation and Formulation: A Practical Guide for Candidate Drug Selection to Commercial Dosage Form. Boca Raton, FL: CRC Press; 2004:515-569.

10. Mahalingam R, Li X, Jasti B. Semisolid Dosages: Ointments, Creams, and Gels. In: Pharmaceutical Sciences Encyclopedia: Drug Discovery, Development, and Manufacturing. Hoboken, NJ: John Wiley \& Sons, Inc; 2010

11. Crowley MM. Solutions, emulsions, suspensions, and extracts. In: Felton L, ed. Remington: Essentials of Pharmaceutics. London, UK: Pharmaceutical Press; 2013:448-457

12. International Conference on Harmonization. Q8 ICH. International Conference on Harmonisation of Technical Requirements for Registration of Pharmaceuticals for Human Use. ICH Harmonised Tripartite Q8 (R2) Guideline: Pharmaceutical Development. Geneva, Switzerland: ICH; 2009. Available at: http://www.ich.org/fileadmin/Public_Web_Site/IC H_Products/Guidelines/Quality/Q8_R1/Step4/Q8_ R2_Guideline. pdf. Accessed July 17, 2018

13. Aswal A, Kalra M, Rout A. "Preparation and evaluation of polyherbal cosmetic cream" Der Pharmacia Lettre. 2013; 5(1):838

14. Pratikcha R, Adarsh P, Sujit Das, Pharmaceutical Creams and their use in wound healing: A Review, Journal of Drug Delivery \& Therapeutics. 2019; 9(3-s):907-912

15. Bauer JF. Polymorphism-A critical consideration in pharmaceutical development, manufacturing, and stability. J. Valid. Technol. 2008, 14, 15-24 